\title{
Continuing Education for Professional Development in Higher Education Teaching
}

\author{
Jacques de Lima Ferreira1, Gisele Rietow Bertotti² \\ ${ }^{1}$ Graduate Strict Sense Program of Education and New Technologies, Centro Universitário \\ Internacional-UNINTER, Curitiba, Brazil \\ ${ }^{2}$ Pontifical Catholic University of Paraná, Curitiba, Brazil \\ Email: drjacqueslima@hotmail.com, gisele.rietow@pucpr.br
}

Received 30 May 2016; accepted 9 July 2016; published 12 July 2016

Copyright (C) 2016 by authors and Scientific Research Publishing Inc.

This work is licensed under the Creative Commons Attribution International License (CC BY). http://creativecommons.org/licenses/by/4.0/

(c) (i) Open Access

\section{Abstract}

This paper presents a qualitative research of the case study type that was held with professionals from various fields of knowledge (law, nursing, administration, education, accounting, medicine, physical therapy, journalism, economics, engineering, etc.), undergraduates who participated in a continuing education course, specifically, a specialization in continuing education to work in higher education in a community institution. The research problem that guided the research was: What are the contributions, implications and impacts of continuing education for teaching in higher education from the perceptions of professionals from various fields of knowledge? The research aimed to analyze the professionals' repercussions of the process of continuing education for the practice of teaching in higher education. The research involved three classes of specialization of the following years: 2013, with 25 students; 2014 with 22 students and 2015 with 23 students, totaling 70 subjects investigated. Data were collected from a questionnaire with open and closed questions which has enabled content analysis from the perspective of Bardin (2011) with the help of Atlas Ti software. The results showed that the participation in the continuing education course contributed to teaching in higher education through the possibility of obtaining pedagogical knowledge and practical application of these, which culminated in a reflection on pedagogical practice, impacting directly on the professional work of these teachers, who only felt the lack of a more detailed work with the education of the distance mode.

\section{Keywords}

Continuing Education, Teaching, Higher Education, Teacher's Professional Development

\section{Introduction}

Higher education in Brazil has changed a lot in recent decades, changes which were influenced by social de- 
mands seeking for improvements and advances in democratization of this level of education, coupled with the impact of information and communication technologies on the various areas of knowledge. Higher education has become complex because the university receives a wide variety of students from different social and economic levels that mostly use technologies to communicate and learn, and consequently, it is important that the teacher in higher education knows how to use educational technologies as a resource in favor of the process of teaching and learning, that he/she recognizes that it is not the only source of information to students that learning in higher education involves aspects related to professional practice, skills and abilities that need to be developed and worked in harmony with the values and attitudes of contemporary society.

In the circumstances described above, changes in the university context, teachers face challenges and dilemmas constantly, which make them seek qualification, knowledge and methodologies for teaching which make them able to meet the new demands of higher education. The hiring of teachers ${ }^{1}$ in universities requires qualification and experience which in turn often becomes insufficient to teach in higher education. It is necessary to be in constant search for knowledge, for continuing education and professional development since the university teacher urgently needs to relearn how to be a teacher due to a number of issues that are latent in this universe as pedagogical knowledge, diversity and inclusion of students, the use of technology, teaching with research, active methodologies, peer learning in college, collaborative learning, among others.

The number of students who entered colleges increased considerably and consequently the confrontations and challenges that teachers face in teaching and learning are many. Given this perspective, the university seeks to hire teachers that work in this context with professionalism and scientific and pedagogical knowledge. Therefore, for this to happen, it is necessary specific continuing education to work in higher education, since many teachers, except educators and licentiates, who have not been trained to be teachers and often have no knowledge on teaching in higher education. The vast majority of teachers in universities became teachers on the practice they perform without pedagogical knowledge without specific training to do so.

Given the necessity of continuing education for teaching in higher education, the research of this paper presents the perceptions of undergraduates of a specialization that aims to provide continuing formation for undergraduates who have completed their college course and aim to teach in their respective professional areas. The specialization is called "Teacher's continuing education to work in higher education" aims to prepare professionals to practice teaching in the university context on the development and deepening of theoretical knowledge and practical relevant to the teaching activities in the classroom and distance contexts. Therefore, it seeks the understanding of educational concepts, the condition of pedagogical acting and didactic activities in the reality of higher education. This specialization course is offered annually by a large community college in the city of Curitiba and was designed before the new demands of university education, the expansion of places, the need for curricular restructuring and teaching methodologies for teaching, research and dissemination of this action in the social context, without forgetting the need for the use of technology in teaching practice as a resource in favor of education.

The specialization occurred in classroom mode, the classes took place weekly; 3 times a week in the evening for a year, from March to December and the workload was 360 hours. The continuing education course offered the following subjects: teaching action in higher education, educational concepts; teaching, curriculum, educational policies, planning, evaluation, technological resources, distance education and teaching practice. The students performed teaching practice at the same university.

The investigation of this paper presents a qualitative approach of a case study type that was performed in three groups of undergraduates of the specialization from the years 2013, 2014 and 2015 and had as research problem the following question: What are the contributions, implications and impacts of continuing education for teaching in higher education from the perceptions of professionals from various fields of knowledge? In the search for answers to the problem that guides this research, we aim: to analyze the professionals' repercussions to the process of continuing education for the practice of teaching in higher education. Therefore, it is initially made a reflection on the continuing education for teacher's professional development. In the second phase, the methodological procedures used in this study are explained. Finally, a content analysis from the perspective of Bardin (2011) with the help of Atlas Ti software is performed and the search results are displayed.

\footnotetext{
${ }^{1}$ In Brazil there are two kinds of university professors: the ones who finished the under graduation course and continued their education at the expertise level, which here is called: specialization and the ones who have master or PhD degree, the so-called professors. In this study, they only had finished the under graduation level.
} 


\section{Continuing Education for Teacher's Professional Development}

Continuing education is in a relatively new area of study, since studies in this area began to be developed from the Law of Directives and Bases of Education in the 1990s (Brazil, 1996), referred to as "continuing professional development” Article 67. This insertion occurs in a context of perpetuation of the neoliberal ideal figure from finding the mismatch between the education offered and the needs of the labor market (Shiroma, Moraes, \& Evangelista, 2007).

In addition to the strong influence suffered by the adopted socio-economic model, education also was funded by multinational organizations and the transfer of educational policies based on foreign models that prioritized adoption of rates and evaluative rankings, which instilled to education a competitive nature and based on results. This focus on the product resulted in changes in educational practice which, with a view to reducing costs, underwent a process of speed and cheapness, resulting in increasing the supply of spaces in the distance mode, intensification of teaching and intensification of educational products sales (Silva, 2001).

The actions related to continuing education in this period, from a study of the type state of the art, were classified according to the adopted concepts and resulted in the following categorization: acquisition of information /skills, reflective practice within the school and reflective practice with broader sociopolitical dimensions (Carvalho \& Simões, 1999).

In the following decade, the focus on practices which aim to stimulate the teaching reflection on practice now features more strongly (Ferreira, 2003) and they progress gradually to include the ethical and political dimensions beyond the emotional aspect, which provides a new categorization now between practices centered on the teacher and school groups (Davis et al., 2009).

The emphasis on the teacher is highlighted by Vaillant and Marcelo (2012: p. 31) who emphasize the need to think continuing formation as an adult education process, which aims to encourage the development of selftraining, because they consider that "motivation to change is the element that determines that anyone take a chance to look at the other side of the mirror." In this sense, these authors advocate the need to consider teacher's education as part of a teacher's professional development project, introducing not only a new nomenclature for such training, but a design that considers education as a continuum, a process by which the teacher will go throughout life and where he/she is considered as the main agent.

\section{The Methodological Path}

The investigation of this paper aims to analyze the impact of professionals from different areas of knowledge which participated in the process of continuing education for the practice of teaching in higher education in the form of a specialization. To accomplish the objectives of this research was chosen the qualitative approach of a case study, interpretative nature. Qualitative research allows the researcher to interpret the educational phenomenon before its reality and its surroundings. In this perspective, the researcher can establish a real interpretation of events and educational events in the quest to understand the complexity of education and educational processes. According to Chizzotti:

Qualitative research covers, today, a cross-disciplinary field involving the humanities and social sciences, assuming traditions or multiparadigms of analysis derived from positivism, phenomenology, hermeneutics, Marxism, critical theory and constructivism, and adopting multimethod research for the study of a phenomenon located in the place where it occurs, and finally, seeking not only to make sense of this phenomenon but also interpret the meanings that people give to them (Chizzotti, 2006: p. 28).

The research is enriched by engaging an investigation of the case study type, by allowing detailed investigation of a specific case, in this paper, the observation of the continuing education course, specialization, designed to train teachers for higher education. The case study allows the researcher to develop his/her vision in detail in specific situations. According to Bogdan and Biklen (1994: p. 89) “[...] the case study is the detailed observation of a context or individual from a single source document or a specific event.”

The chosen sample for the research and application of data collection instruments were undergraduates of specialization titled: “Teacher's continuing education to work in higher education” of a community college in the city of Curitiba, from the years 2013, 2014 and 2015. The undergraduates of the 2013 class mostly consisted of women over thirty years who opted for teaching in higher education because they see in teaching the possibility of a promising career, in other years investigated this trait remained. Of the 25 students of specialization, 19 
are female and 06 are male.

The 2014 class consisted of 22 students also showed more women in specialization, 15 female and 07 male. The 2015 class had 23 students, 12 female and 11 male. In Brazil the teaching career has many women, especially in higher education in the area of human and health sciences. The total number of investigated subjects was 70 graduating students of specialization, 46 are female and 24 male. Of the 46 women, the initial formation extends to several areas of training such as Education, Nursing, Nutrition, Journalism, Physiotherapy, Law, among others. Of the 24 men who carried out the expertise, initial training was carried out in areas such as Medicine, Engineering, Accounting, Economics, Management, among others.

All the subjects have completed specialization and after three months answered a questionnaire with 09 open questions and 05 closed questions which inquired contributions, implications and impacts of continuing education for higher education teaching. The data collection instrument was developed in Google Docs and sent by email to the graduates. The anonymity of the subjects occurred during all stages of data collection and for data analysis. The Free Consent Agreement was made available to the research subjects along with the questionnaire, all graduates involved are over eighteen years and accepted freely to participate in the investigation.

Questionnaires were received by e-mail and coded in such a way as to enable the realization of the content analysis and ethical research. Questionnaires were coded as follows:

-The acronym QF stands for training questionnaire.

-The numerical expression 01 corresponds to the subject who participated in the research, identification.

-The numerical expression in 2013 is the year that the egress finished specialization.

All these information together formed a QF012013 code that has the following meaning: training questionnaire of the subject 01 , from 2013 year of specialization. For each completed questionnaire was created a code with this information. After the questionnaires were identified by a code, they were added to qualitative data analysis software Atlas Ti in its version for the Mac to start the process of content analysis from the perspective of Bardin (2011), as shown in Figure 1.

This entire process of identification and coding was done in the 70 questionnaires answered by the research subjects from the mentioned years.

\section{The Analysis Process of Collected Data}

The data analysis is a very important part that helps the researcher in the organization and interpretation of data collected. At this stage of the research, the researcher seeks to organize and structure the data to identify a meaning, a meaning that can represent data showing evidence of research. According to Creswell (2014), data analysis:

[...] qualitative research consists in the preparation and organization of data (i.e., text data such as transcripts, or data images as photographs) for analysis after reducing data in areas through a process of creating and condensation codes and finally, the representation of data in figures, tables or discussion (Creswell, 2014: p. 147).

Data analysis in qualitative approach is dynamic and varied; the researcher may choose to perform different types of analysis of data to help answer his/her research problem. The researcher, when performing data analysis, needs to be careful in data collection and, especially, have theoretical knowledge about the analysis technique to

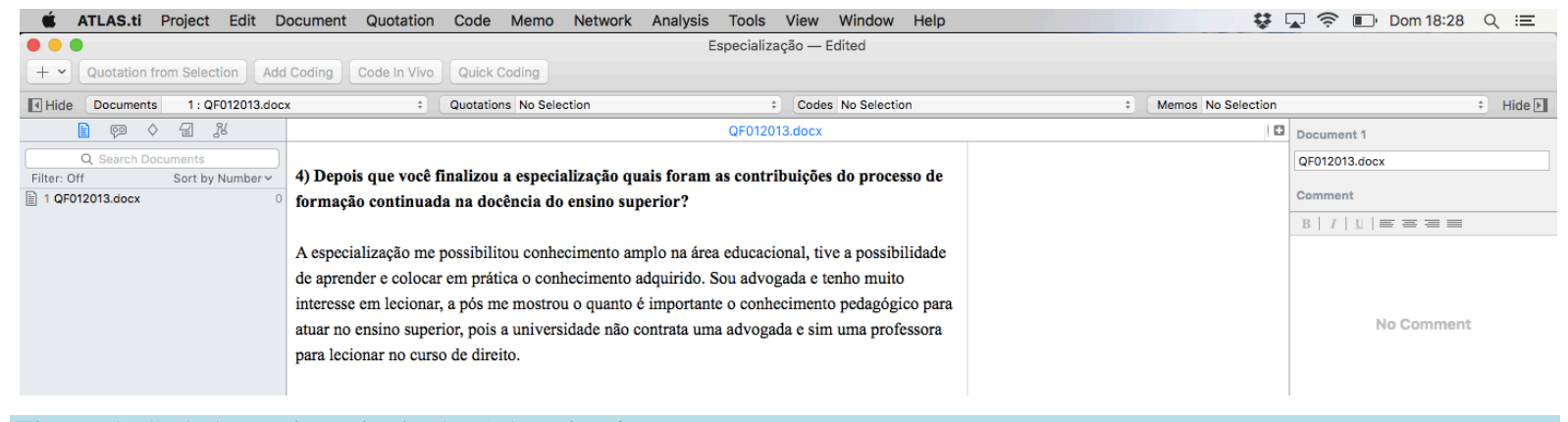

Figure 1. Coded questionnaire in the Atlas Ti software. 
be held. Currently, there are different techniques for organizing and analyzing qualitative data in this paper, we opted for the content analysis from the perspective of Bardin (2011) held in the questionnaires that were sent to graduates of specialization. Content analysis is a possibility as a research technique that can be used in a qualitative approach. It can be performed in various materials in text form from any source. According to Oliveira et al., (2003), the content analysis is an:

[...] interpretative analysis tool, is one of the oldest research techniques-the beginnings of its use dating back to 1787 in the United States, and its emergence as a study method happened in the 20's and 30's of last century with the development of Social Sciences, when classical science went into crisis. As it is known, the interpretive attitude is part of the human being who wants to attain knowledge. Since hermeneutics, art of interpreting sacred texts or mysterious, man practiced interpretation as a way to put his point about a given phenomenon (Oliveira et al., 2003: p. 2).

Bardin (2011: p. 37) clarifies that the content analysis “[...] is a set of communication analysis techniques. It is not only a tool, but a range of implements; or, more accurately, it will be a single instrument, but marked by a large disparity of forms and adaptable to a very wide field of application [...].” Content analysis can also be performed on images and sounds and conduct content analysis can be done in different ways, there is no rule to be fulfilled to reach the end of the analysis process, the researcher has different possibilities to perform analysis to answer his/her search object. Given the various possibilities to perform content analysis, it was decided to take as base the technique of the steps proposed by Bardin (2011) to perform content analysis of questionnaires answered by graduating students. The steps of content analysis from the perspective of Bardin (2011) present the following phases: pre-analysis, material exploration and processing of results. The first step, the pre-analysis, corresponds to the organization of the material collected.

The pre-analysis is aimed at organizing the data, the choice of documents that will be part of the data analysis, the development of indicators, codes that facilitate the analysis. At this stage of content analysis, formative questionnaires were organized and we created a code to identify each completed questionnaire. We had as corpus (set of documents used) of content analysis all questionnaires (70 formative questionnaires).

In the exploration phase of the material is the time in which the researcher performs content analysis, the systematic application of technical analysis. At this stage we proceeded the encoding, which is the creation of codes from reading the responses of the data collection instrument. It is the organization of data to later perform the categorization. According to Bardin categorization "[...] corresponds to a transformation-made according to precise rules-the raw text data, processing this that, by clipping, aggregation and enumeration, achieves a representation of the content or its expression; likely to clarify the analyst about the features of the text” (Bardin, 2011: p. 133).

Encoding is the systematic organization that is done to further classify and categorize. After encoding the next step is the categorization, which according to Bardin (2011) is:

[...] a classification operation of the components of a set of differentiation and then by regrouping according to gender (analogy), with pre-defined criteria. The categories are rubrics or classes, which bring together a group of elements (recording units, in the case of content analysis) under a generic title, this group made because of the common characteristics of these elements (Bardin, 2011: p. 147).

Still in the exploration phase of the material, after the data encoding was performed categorization which is presented with a process that allows the codes to be grouped, segregated or grouped with the aim of consolidating a meaning.

In the results treatment phase, according to Bardin (2011: p. 131) “[...] the raw results are treated in order to be meaningful and valid" [...] and the researcher "[...] with at his/her disposal significant results and faithful, can then propose inferences and interpretations and advance the purpose of the planned objectives—or which concern other unexpected discoveries."

The content analysis in the formative questionnaires which graduates of specialization responded used the Atlas Ti software, which allows the researcher to perform the analysis on a large amount of data. According to Gibbs (2009), qualitative data analysis software provide facilities and advantages to organize and analyze data, make it easier and more accurate, however, the software does not perform the analysis of the data, who analyzes the data and makes the relationship with its object of study is the researcher. According to the author, the qualitative data analysis software has tools which allow: 
[...] manage encoding and access to texts combined with sophisticated searches. The encoding and access not only facilitate the selection of text snippets (or parts of images) and the application of codes, but also make it easier to access all encoded texts in the same way without descontextualization, ie, without losing any information about the origin of this text. These programs can help in the analytical process; they offer a number of instruments to examine features and relationships (Gibbs, 2009: p. 137).

The Atlas Ti is a qualitative data analysis software widely used in the area of education research, it allows the management, organization, grouping and regrouping of the data. Queiroz and Cavalcanti (2011) emphasize the potential of the software and point out that it can perform:

[...] longitudinal analysis and manage different types of documents or data collection tools, such as answers to open questionnaires questions, observation reports, letters, even all texts expressed in written form, as well as audio (interview transcript unstructured, songs, meetings, lectures and other images (photos, drawings, paintings, etc.) and videos (from television reports recordings, classes, films) (Queiroz \& Cavalcanti, 2011: p. 3).

To illustrate the steps of content analysis in the training questionnaire with the help of Atlas Ti software, is presented in Figure 2 the steps of the data analysis process carried out and its explanation.

Step 1. Pre-Analysis-Organization of data: The data placed in the software come from the formative questionnaire sent by email to graduates of specialization in teacher's continuing education to work in higher education, courses of the years 2013, 2014 and 2015. The questionnaire was developed in Google Docs and sent by email to the graduates. In all questionnaires encoding was performed.

Step 2. Using the software Atlas Ti: We used the content analysis in all formative questionnaires, 70 questionnaires received by email. Questionnaires were identified by a code that followed the following name: QF (Formative Questionnaire), 01 which corresponds to the identification of graduates who attended the specialization and year. Example: QF212015 this code means-training questionnaire egress 21 of the year 2015. The coded questionnaires were saved in PDF format and inserted Atlas Ti software to start the analysis process.

Step 3. Exploration of the material: In the exploration of the material, the formative questionnaires that are in the Software Atlas Ti passed through two stages: the coding and categorization, these steps correspond to the analysis of open and closed questions of the questionnaire. For each question and answer of the questionnaire a code was created.

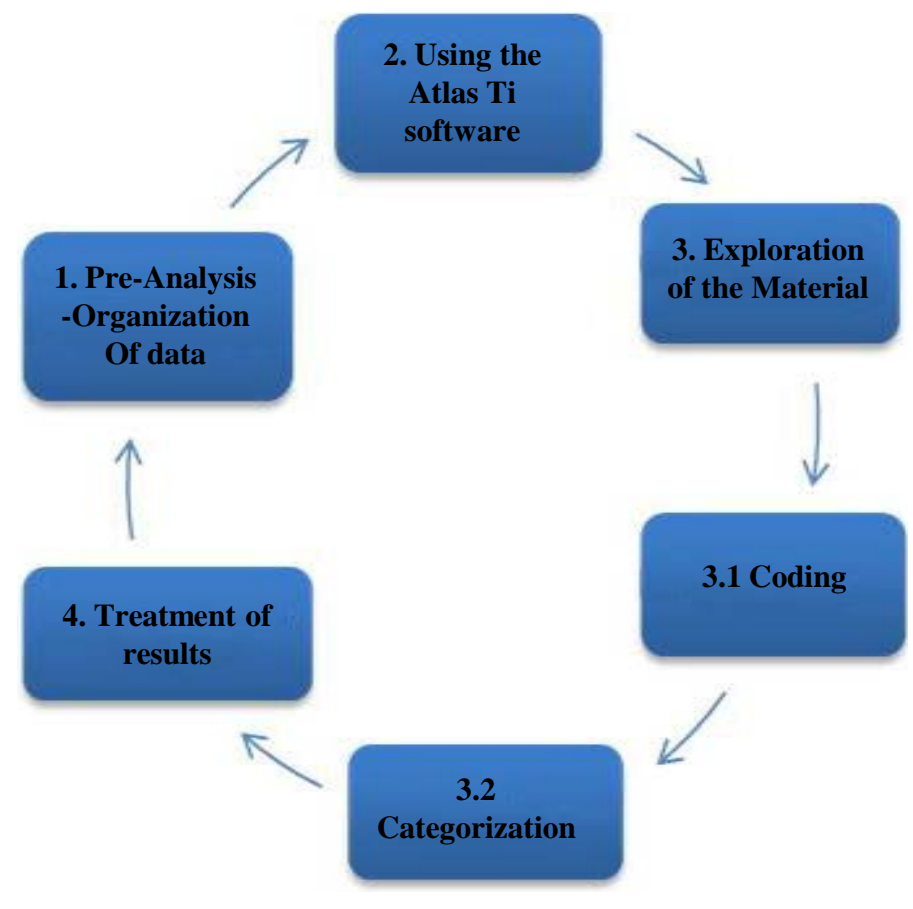

Figure 2. Stages of content analysis with the help of Atlas Ti software. 
Step 3.1. Coding: The step of coding was performed with the creation of codes to perform the categorization. The codes represent a system of symbols which allows the representation of information. The codes were created from the moment you start reading the questionnaire responses. For each response was created a code and the same or similar answers received a code previously created.

Step 3.2. Categorization: Categorization is the union or the set of codes for incidence or similarity which allows researchers to group the data to reinforce meaning. The codes were grouped by similarity and incidence led the analysis categories.

After finishing coding, it was visualized Atlas Ti the code which had the highest incidence and similar responses. All codes with the highest incidence and similar responses were analyzed by the researchers. The code analysis was performed as follows: 1-careful reading of the responses of graduates; 2-Reflection of researchers on each response; 3-Identification and creating of groups with points of convergence between the answers to consolidate a meaning; 4-Creation of categories from the responses of graduates.

Step 4. Treatment of results: Knowing the answers of the participants, they began to establish themselves as indicators for the creation of categories. For this, the researchers sought the meaning and direction of the responses of graduates and to the extent that they were also interested in knowing the intensity of the appearance of logical semantic meanings for that, they decided to quantify the absolute and relative frequencies of responses. For the analysis of the content held in the questionnaires, it was prepared a table showing the categories created and some of its indicators (replies). The table presented below, has three answers that were used as examples for the creation of categories and the total number of responses in each category. The questions were chosen 12, 13 and 14 with responses that help to answer the research problem.

In the formative questionnaire we asked to graduates: What are the contributions of the specialization to your training in higher education teaching? The answer with the highest incidence to this question was that the expertise provided knowledge about teaching in higher education, with 54 incidents. The question was intended to identify the contributions of specialization for the graduates' education. According to Table 1, we present the categories that were created from the participants' responses:

In Table 1, we found that 38 graduates mentioned that pedagogical knowledge is related to teaching activities, teaching is a science that is dedicated to the education process, it is essential for the formation of a teacher. On the responses of graduates, we, researchers, also agree that pedagogical knowledge is essential to perform the action of teaching, concerning issues related to teaching and learning that allow the teacher to build knowledge with his/her students. Scientific knowledge of professional training area linked to the pedagogical knowledge enables teachers through their teaching to be able to overcome the challenges in the process of teaching and learning. In the twenty-first century, education is still based on the reproduction of knowledge, the teacher

Table 1. Some reasons set out by the students of the research to justify the contributions of the specialization for training in higher education teaching.

\footnotetext{
Responsesxplicitados

(CATEGORY)-Pedagogical Knowledge to act in Higher Education

"The pedagogical knowledge that I had contributed so I can relate knowledge of my training with the pedagogical to work as a teacher knowing what to do about the organization, preparation and execution of a class”.

"The pedagogical knowledge that I got made me realize that without the theoretical and practical foundation the teacher cannot transmit and build knowledge with their students".

"Without pedagogical knowledge the teacher often performs his/her action within the classroom without knowing in fact what he/she is doing, this knowledge is essential to teach [...]”.
}

\section{(CATEGORY)-Practical knowledge to teach}

"During my training the specialization provided me with the practical knowledge of how to teach a class, from its planning to the completion of the class”.

"The specialization has contributed a lot in my training; being able to put into practice the knowledge acquired was very good”.

"No doubt, learning about educational concepts, reading and understanding the educational process in higher education helps a lot, but the fact of studying and putting into practice the knowledge acquired left me safer to act as a teacher in higher education, the relation between theory and practice is essential”.

\section{Graduates}

Total of

responses: 38

QF122014

QF072015

QF202015

Total of

responses: 16

QF092013

QF112014

QF232015 
who presents pedagogical knowledge in his/her training tends to build knowledge with his/her student, is concerned with learning and places himself/herself as mediator of this process.

In the formative questionnaire, the question 13 inquired to graduates: What are the implications of specialization for your training in higher education teaching? The answer with the highest incidence to that question mentioned the lack of practical classes in the subject distance education, with 39 incidents. The question was intended to assess the implications of specialization for the training of graduates. According to Table 2, we present the categories that were created from the responses of the participants:

In the process of continuing education, the teaching activities in higher education have been incorporated into classroom and distance modes, with specific subject for distance education, students had the opportunity to discuss and reflect on the role of the teacher in this type of education. According to the responses, 21 graduates said that during the process of continuing education, have not worked satisfactorily the practical classes for the mediation in distance education. In the distance the mediation is an extremely important teaching activity, since it allows the teacher to build with his/her student knowledge, is the relationship between teacher and student that happens to the process of teaching and learning, is when the teacher puts himself/herself as a facilitator, motivator, motivating learning, which contributes to the student to learn. The lack of pedagogical practice of mediation in the formation of a teacher can compromise the process of student learning, as in distance education the teacher has an important role and his/her acting is totally different from what happens in the classroom teaching. It is necessary and important to work with the mediation in practice so the students can realize the difference.

In the formative questionnaire, question 14, wondered the following: What are the impacts of specialization for your training in higher education teaching? The answer with the highest incidence to this question is related to the difficulty students have in understanding the educational theories, with 62 incidents. The question was intended to assess the implications of specialization for the training of graduates. According to Table 3, we present the categories that were created from the participants' responses:

In the students' formation process, either initial or continuing, it is important that the teacher contextualizes the linked theory to practice, that theory has practical reflection on the reality of the student. To make them

Table 2. Some reasons set out by the graduates of the research to justify the implications of specialization for training in higher education teaching.

Responses
(CATEGORY)-Practical Approach to Pedagogical Mediation in Distance Education
“[...] I missed a practical lesson to teach the way to mediate
pedagogically the educational process in distance education”.
"I have already worked as a tutor on a course in my area of training and saw that in your course you give emphasis to
form the teacher to work in the classroom teaching and distance teaching, we had lectures about it, but we did not
conduct practical classes on the teacher's mediation in distance education”
“[...] The theory was covered in class, but the practice of mediation process did not happen”.

\section{(CATEGORY)-Practical Approach to Interaction in Distance Education}

"The specialization included the distance education, but we did not have the practice of the teacher interacting with students [...]”.

"I missed performing interaction with students of distance education to feel like the teacher does the teaching process in this modality".

"[...] there was a lack of interaction, the practical part of how this occurs in distance education, how to accomplish this $[\ldots]$...

(CATEGORY)-Practical Approach to perform evaluation in distance education

"We had many practical lessons in the specialization but on the assessment of the matter in distance education I do not feel prepared to do this in distance education I have worked as a tutor and not as a teacher [...]”.

Graduates

Total of

responses: 21

QF062014

QF082013

QF212013

Total of responses: 10

QF232015

QF022013

QF152013

Total of responses: 08

QF122014

QF192014 practice of this".

"I do not have complaints about the specialization, I think it should have more practical classes in distance education, I, for example, missed the opportunity to perform a practical activity to learn how to assess the students, if they really learned at distance".

Source: Table built from the collected data.
QF132015 
understand the theory and relate it to the practice makes meaningful learning, especially when the student has no experience or knowledge about the subject matter. It is complex the process of relation between theory and practice, the teachers need to relate the study subject to a practical context, knowledge, so that the student may establish relations. For graduates of the specialization course, which are from different areas of knowledge, knowledge of educational theories, it is essential for the teacher to put into practice the pedagogical knowledge. The understanding of the issues addressed in education may initially seem strange to the professional who has training in other areas of knowledge, but with proper appropriation and understanding of the theory and its relationship with practice, the connections of the teaching and learning process will be materialized, acquiring sense and meaning to the teacher.

\section{Final Considerations}

Considering the data collected in this study, it is concluded that participation in the specialization course investigated contributed to teaching in higher education since it enabled the obtainment of pedagogical knowledge, which, in the participants' opinion, helped to develop the ability of transposition of the theory into practice with greater confidence in the pedagogical action, showing a direct impact on professional performance. This finding relates to the studies on teachers continuing education which demonstrate its use as a way to remedy deficient aspects of undergraduate courses (Davis et al., 2009) in which the emphasis on theoretical aspects implies a devaluation of the pedagogical part (Gatti, Barreto, \& André, 2011) and denotes the need of pedagogical deepening which is also pointed out by teachers from bachelor's degree programs who have chosen to follow a teaching career.

Another factor that confirms an aspect mentioned as important in the theoretical framework of the continuing education area ratified by this research concerns the importance of linking the theoretical reflections to the practical nature of activities since a quarter of the participants highlighted as positive the opportunity to put into practice what was studied in the classroom.

The acquisition and application of theoretical and practical knowledge conduced a reflection about the pedagogical practice of those who have already worked in higher education and provided confidence gained in their work. However, some aspects highlighted by the study participants, draw attention to some implications that involve the difficulty in dealing with distance education, and the realization of the need for inclusion of practical activities, interaction and on working with the assessment with that type of education. It would therefore be advisable to take into account the teachers' observation and seek to implement it in the next groups.

Table 3. Some reasons set out by the graduates of the research to justify the impacts of specialization for training in higher education teaching.

\begin{tabular}{|c|c|}
\hline Detailed Responses & Graduates \\
\hline (CATEGORY)-Understanding the educational theories to put them into practice as a teacher & $\begin{array}{l}\text { Total of } \\
\text { responses: } 57\end{array}$ \\
\hline $\begin{array}{l}\text { "[...] what impacted me was the difficulty to understand the education theories to use it in my practice as a teacher, the } \\
\text { education sector is complex, a number of elements interfere in the teaching process". }\end{array}$ & QF032015 \\
\hline “[...] understanding the concepts and theories of education and their use in educational practice [...]” & QF122014 \\
\hline $\begin{array}{l}\text { "When I started the specialization what impacted me the most was the educational language, understanding the } \\
\text { educational theory was difficult, its acceptance in my practice, everything was new, there was no reference and I } \\
\text { was worried about how to use this theoretical knowledge in my practice classroom, how to relate it to accounting”. }\end{array}$ & QF012015 \\
\hline (CATEGORY)-Understanding the educational theories because the formation is not in the educational area & $\begin{array}{l}\text { Total of } \\
\text { responses: } 05\end{array}$ \\
\hline $\begin{array}{l}\text { "[...] when the person is not formed in the educational field is very difficult to understand the educational theories, my } \\
\text { formation area is in the economy, I had difficulty understanding the educational concepts because my basic training } \\
\text { does not address it". }\end{array}$ & QF132014 \\
\hline $\begin{array}{l}\text { "What impacted me at the beginning of the course was the difficulty in understanding the educational theories because } \\
\text { I have no training in this area, everything was new and complicated, but then I started appropriating myself of the } \\
\text { concepts and reading and ended up understanding". }\end{array}$ & QF172014 \\
\hline “[...] the major impact was to understand the theories; I have no training for this [...]. & QF022014 \\
\hline
\end{tabular}

Source: table built from the collected data. 
Regarding the impacts of the training, there was an emphasis on the mention of the difficulties encountered in working with educational theories and transpose them to practice, corroborating the conclusion that this specialization course impacted teachers in the sense of realizing the need to seek theoretical studies about educational theories and stimulated reflection on the need for integration between theory and practice.

Finally, it is concluded that such studies only will cause greater gains if changes in practice can be shared among peers, as ratified by Vaillant \& Marcelo (2012: p. 29), "it is the interrelationship between people promoting learning environments that facilitate the complex development of individuals that form and are formed." Hence the importance of conducting such studies and their dissemination in the scientific community so more people can benefit from this knowledge sharing, thereby contributing to the professional development process.

\section{References}

Bardin, L. (2011). Content Analysis. São Paulo: Edições, 70.

Bogdan, R. C., \& Biklen, S. K. (1994). Qualitative Investigation on Education. Porto: Editora Porto.

Carvalho, J. M., \& Simões, R. H. S. (1999). What Do the Brazilian Journals Say about Teacher's Education and Practice: 1990-1997. Vitória: Universidade Federal do Espírito Santo.

Chizzotti, A. (2006). Qualitative Research in Human and Social Sciences. Petrópolis, RJ: Vozes.

Creswell, J. W. (2014). Qualitative Investigation and Research Project: Choosing among Five Approaches.. Porto Alegre: Penso.

Davis, C. L. F. et al. (2009). Teacher's Continuing Formation: An Analysis of Modalities in Brazialian States and Cities. São Paulo: FCC/DPE.

Gibbs, G. (2009). Qualitative Data Analysis. Porto Alegre: Artmed.

Oliveira, E., Ens, R. T., Andrade, D. B. S. F., \& Mussis, C. R. (2003). Content Analysis and Research in the Education Field. Educational Dialogue Journal, Curitiba, 4, 11-27.

Queiroz, T. L. A., \& Cavalcante, P. S. (2011). The Contributions of Atlas Ti Software to the Analysis of Written Experience Reports. In Congresso Nacional de Educação-Educere (pp. 11775-11787). Curitiba: Pucpr.

Shiroma, E. O., Moraes, M. C. M., \& Evangelista, O. (2007). Educational Policy (4th ed.). Rio de Janeiro: Lamparina.

Silva, M. A. (2001). Teacher Issue on Educational Policy. In C. Cunha, J. V. Sousa, \& M. A. Silva (Eds.), Educational Public Policies in Latin America: Lessons Learned and Challenges (pp. 325-346). Campinas, SP: Autores Associados.

Vaillant, D., \& Marcelo, C. (2012). Teaching How to Teach: The Four Steps of Learning. Curitiba: Ed. UTFPR. 


\section{Appendix}

\section{FORMATIVE QUESTIONNAIRE}

This questionnaire is aimed exclusively to a research on teacher's continuing education to work on higher education.

1. Sex:

( ) Female ( ) Male

2. Age:

( ) 18 to 24 years

( ) 25 to 35 years

( ) 36 to 45 years

( ) 46 to 55 years

( ) More than 55 years

3. Status:

( ) Single

( ) Married

( ) Widower/widow

( ) Divorced

4. Formation

( ) Under graduation

( ) Specialization

( ) Master

( ) Doctorate

5. Have you had any experience as a teacher in any other level?

() Yes

() No

6. What is your initial formation?

7. After you finish the specialization are you going to continue to take courses related to teaching?

8. If you become a teacher now, what subject would you like to teach?

9. During the development of your under graduation, specialization or master have you had information about being a teacher on your area?

10. Why did you choose to take a specialization which aims the formation to teach on higher education?

11. Do you intend to work on your area of formation and be a part-time teacher or be only a higher education teacher?

12. What are the contributions of the specialization to your training in higher education teaching?

13. What are the implications of specialization for your training in higher education teaching?

14. What are the impacts of specialization for your training in higher education teaching?

\section{Submit or recommend next manuscript to SCIRP and we will provide best service for you:}

Accepting pre-submission inquiries through Email, Facebook, Linkedin, Twitter, etc

A wide selection of journals (inclusive of 9 subjects, more than 200 journals)

Providing a 24-hour high-quality service

User-friendly online submission system

Fair and swift peer-review system

Efficient typesetting and proofreading procedure

Display of the result of downloads and visits, as well as the number of cited articles

Maximum dissemination of your research work

Submit your manuscript at: http://papersubmission.scirp.org/ 